\title{
Ceramic coated Y1 magnesium alloy surfaces by microarc oxidation process for marine applications
}

\author{
V V NARULKAR*, S PRAKASH and K CHANDRA \\ Metallurgical and Materials Engineering Department, Indian Institute of Technology, Roorkee 247 667, India
}

MS received 8 March 2007; revised 7 May 2007

\begin{abstract}
The magnesium alloys occupy an important place in marine applications, but their poor corrosion resistance, wear resistance, hardness and so on, have limited their application. To meet these defects, some techniques are developed. Microarc oxidation is a one such recently developed surface treatment technology under anodic oxidation in which ceramic coating is directly formed on the surface of magnesium alloy, by which its surface property is greatly improved. In this paper, a dense ceramic oxide coating, $\sim 20 \mu \mathrm{m}$ thick, was prepared on an $\mathrm{Y} 1$ magnesium alloy through microarc oxidation in a $\mathrm{Na}_{3} \mathrm{SiO}_{3}-\mathrm{Na}_{2} \mathrm{WO}_{4}-\mathrm{KOH}_{-} \mathrm{Na}_{2} \mathrm{EDTA}$ electrolytic solution. The property of corrosion resistance of ceramic coating was studied by CS300P electrochemistry-corrosion workstation, and the main impact factor of the corrosion resistance was also analysed. Microstructure and phase composition were analysed by SEM and XRD. The microhardness of the coating was also measured. The basic mechanism of microarc coating formation is explained in brief.

The results show that the corrosion resistance property of microarc oxidation coating on the Y1 magnesium surface is superior to the original samples in the $3.5 \mathrm{wt} \% \mathrm{NaCl}$ solutions. The microarc oxidation coating is relatively dense and uniform, mainly composed of $\mathrm{MgO}, \mathrm{MgAl}_{2} \mathrm{O}_{4}$ and $\mathrm{MgSiO}_{3}$. The microhardness of the $\mathrm{Y} 1$ magnesium alloy surface attained $410 \mathrm{HV}$, which was much larger than that of the original Y1 magnesium alloy without microarc oxidation.
\end{abstract}

Keywords. Magnesium alloy; ceramic composite coatings; microarc oxidation; corrosion resistance.

\section{Introduction}

Magnesium is a metal with the lightest weight among all the structural materials. It and its alloy have many traits in application, including high specific strength and stiffness, low elastic modulus, excellent damping capacity, stronger vibration load resistance, fine processing or machinability, little dimensional change, etc. Its highest advantage is sought in marine applications (Jiang et al 2004). Magnesium alloy $\mathrm{Y} 1$ contains $\mathrm{Al}$ and $\mathrm{Zn}$ as alloying elements. Due to these elements, Y1 finds marine applications like side panels, floor plates, moldings, ship structures, etc. But in marine environment, its corrosion is fast and also pitting of surface further degrades its properties. The major techniques for solving these problems include electroplating, chemical plating, anodic oxidation, chemical conversion coatings, physical vapour deposition, surface coating and laser surface treatment and so on, but all of them have certain limitations (Robert and Alivait 1977; Dittrich et al 1984; Kurze and Krysmann 1986).

Microarc oxidation is also called microplasma oxidation or anodic spark deposition, a new surface treatment technology developed recently, which has become a hot-

*Author for correspondence (vinaynarulkar@gmail.com) spot of international researches (Wirta and Brown 1991; Kurze 1994; Zozulin and Bartak 1994). It breaks the limitations of traditional anodic oxidation operating voltage. By introducing the work zone into the high-voltage discharge zone, ceramic coating is directly formed on the surface of nonferrous metals (also called valve metals) such as $\mathrm{Al}$, $\mathrm{Ti}$ or $\mathrm{Mg}$, etc with the high instant temperature in the microarc zone. Ceramic has become the third generation of engineering materials to follow steel and aluminum for its special physical and chemical features, but its poor properties in machinability limit its application. Through microarc oxidation, in situ grown ceramic coating is directly formed on the surface of magnesium alloy, which makes the perfect combination of the second or third generation of engineering materials possible (Wenbin et al 1998; Gnedenkov et al 2001).

\section{Experimental}

\subsection{Materials and methods}

Experimental material adopts Y1 magnesium alloy which is an $\mathrm{Mg}-\mathrm{Al}$ wrought magnesium alloy with chemical components (wt \%) including Al 3.2 3.5\%, Zn 0.7 1\%, Mn $0.2 \sim 1.0 \%, \mathrm{Si} \sim 0.05 \%, \mathrm{Cu} \sim 0.01 \%$ and remaining contents 
of $\mathrm{Mg}$. A specially created marine environment is used for testing this sample. As a device used for surface treatment, self-designed $30 \mathrm{~kW}$ pulse microarc oxidation device consists of pulsed ionizing power supply, electrolytic bath, rabbling system, cooling system, equal-electrode workpieces and copper plate. The samples are $\varphi 20 \times 5 \mathrm{~mm}$ round cakes. The electrolytic solution is mainly composed of $\mathrm{Na}_{2} \mathrm{SiO}_{3}(10 \mathrm{~g} / \mathrm{L})$ prepared with deionized water and some additional additives such as $\mathrm{Na}_{2} \mathrm{WO}_{4}, \mathrm{KOH}$ and $\mathrm{Na}_{2}$ EDTA.

The sample is kept in an electrolytic solution of $\mathrm{Na}_{2} \mathrm{SiO}_{3}(10 \mathrm{~g} / \mathrm{l})$ and a current of $300 \mathrm{~V} / 3 \mathrm{~A}$ is passed for some time (usually in minutes). This will cause oxidation of surface under maintained conditions and a dense thick oxide layer would be formed on the surface. Thickness, cross-sectional microstructure, surface morphology and phase structure of the sample are measured using S250MK3 English scanning electron microscope (SEM) and Rigaku D/max 2500 X-ray diffractometer (XRD). The corrosion resistances of magnesium alloy before and after microarc oxidation are tested through CS300P electrochemical corrosion testing system. The samples are cleaned in acetone, alcohol and distilled water. At room temperature of $20 \pm 2{ }^{\circ} \mathrm{C}$, the corrosive medium is $3.5 \mathrm{wt} \%$ $\mathrm{NaCl}$ solution, reference electrode is saturated calomel electrode (SCE), auxiliary electrode is Pt electrode, and corrosion time is $2 \mathrm{~h}$.

\section{Results and discussion}

\subsection{Microstructure of microarc oxidation ceramic coating}

Figure 1 is a cross-sectional microstructure of microarc oxidation ceramic coating of Y 1 magnesium alloy at 300 $\mathrm{V} / 3 \mathrm{~A} / 40 \mathrm{~min}$. The thickness of the oxidized ceramic coating is about $20 \mu \mathrm{m}$. The microarc oxidization coating consists of three layers including loose layer (I), compact layer (II) and contact layer (III). The loose layer takes up $30 \%$ or so of the total thickness, compact layer, $40-50 \%$, and contact layer between dense layer and metal surface. Oxide and basal body form a typical alloy by penetrating and joining to each other.

\subsection{Analysis of microhardness of microarc oxidation ceramic coating}

Microhardness curve of microarc oxidation ceramic coating over a treatment time of Y1 magnesium alloy at $300 \mathrm{~V}$, $3 \mathrm{~A}$ is shown in figure 2. A load of $15 \mathrm{~kg}$ was used for testing. The microhardness of magnesium alloy surface obviously increased after microarc oxidation, but change of the hardness is not always proportional to time. At the initial stage of microarc oxidation, the microhardness increased over passing of treatment time.
However, it reached $410 \mathrm{Hv}$, three times the original material microhardness after $40 \mathrm{~min}$, and then the microhardness reduced over treatment time passing afterwards. The thickness of oxide film formed on the sample surface increased over a treatment time at the initial stage, which made its hardness to increase continuously. After its thickness reached the maximum value, the oxide film formed for the first time was broken through and big holes appeared on the sample surfaces, which resulted in reduction in thickness and hardness. If the treatment time continued to extend, the oxide film formed on the sample surfaces for the second time, and then its thickness and hardness continually increased. Further increase in holding time caused oxide layer to form but due to improper bonding between layers, these films broke into small chips and also resulted in very brittle oxide coating (Apelfeld et al 2000).

\subsection{Surface morphology of microarc oxidation ceramic coating and XRD phase analysis}

The surface morphology of microarc oxidation ceramic coating is shown in figure 3. Many chimbs and holes can be seen on the surface of magnesium alloy oxide film. All of them are bigger than those on the magnesium alloy surface. The film surface is on the surface. The whole surface of microarc oxide film is a porous surface, which is loose and rough due to uneven melt solids. In addition, obvious extended cracks can be seen on the surface. These cracks are caused by overlarge thermal stress in fast composed grains with different diameters, which are

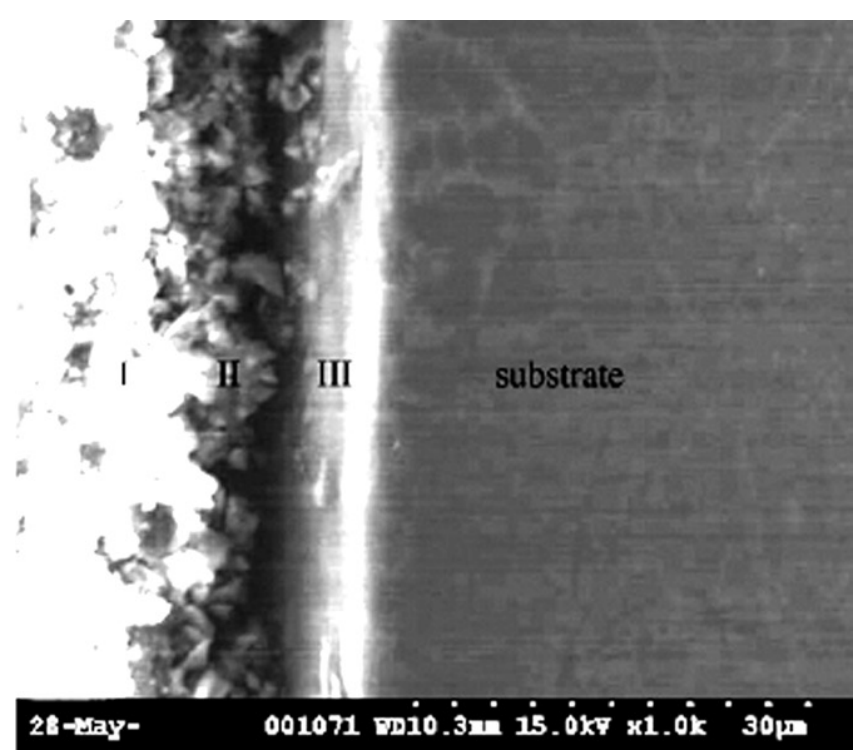

Figure 1. Microstructure of microarc oxidation ceramic coating (300 V, 3A, $40 \mathrm{~min})$. Here I, II and III indicate the layer of coatings formed subsequently. 
melt and unevenly distributed solidification of melts when the film surface comes into contact with the solution (Wenbin et al 1997, 1999; Wenbin and Zhiwei 2000; Bailing et al 2003).

Figure 4 shows the diagram of XRD of microarc oxidation ceramic coating. The microarc oxidation ceramic coating is mainly composed of cubic $\mathrm{MgO}$, and $\mathrm{MgAl}_{2} \mathrm{O}_{4}$ sharp spinels as well as a little amount of $\mathrm{MgSiO}_{3}$, which di-
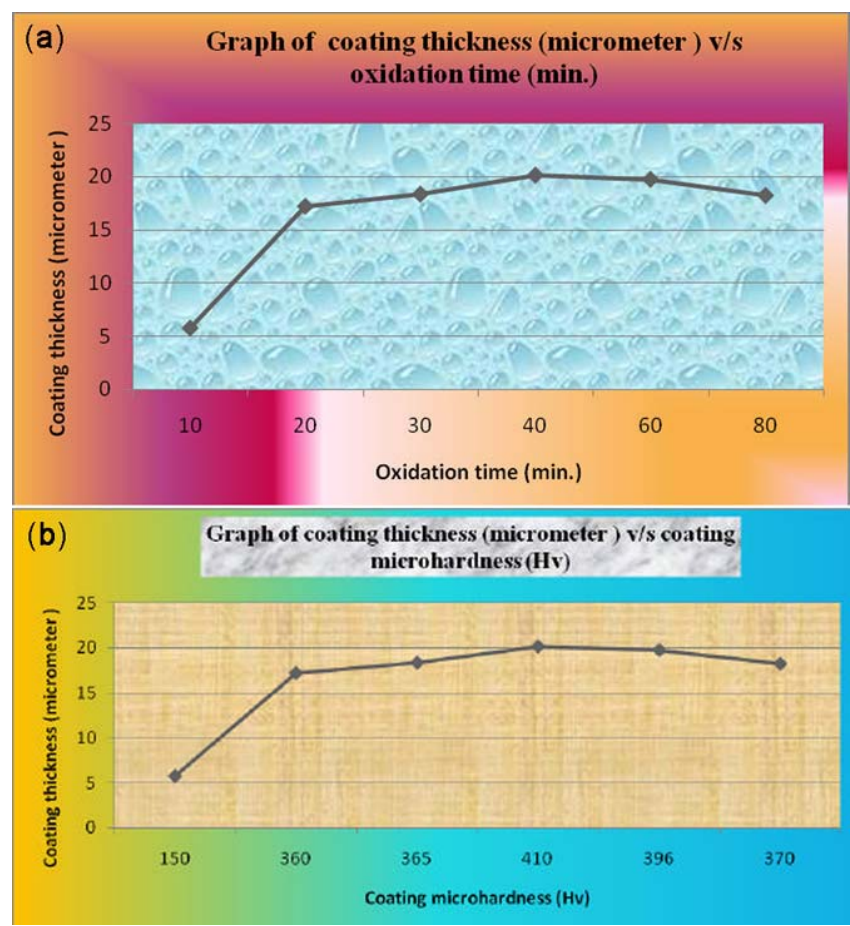

Figure 2. (a) Graph of coating thickness $(\mu \mathrm{m})$ vs oxidation time (min) and (b) microhardness curve of microarc oxidation ceramic coating over a coating thickness.

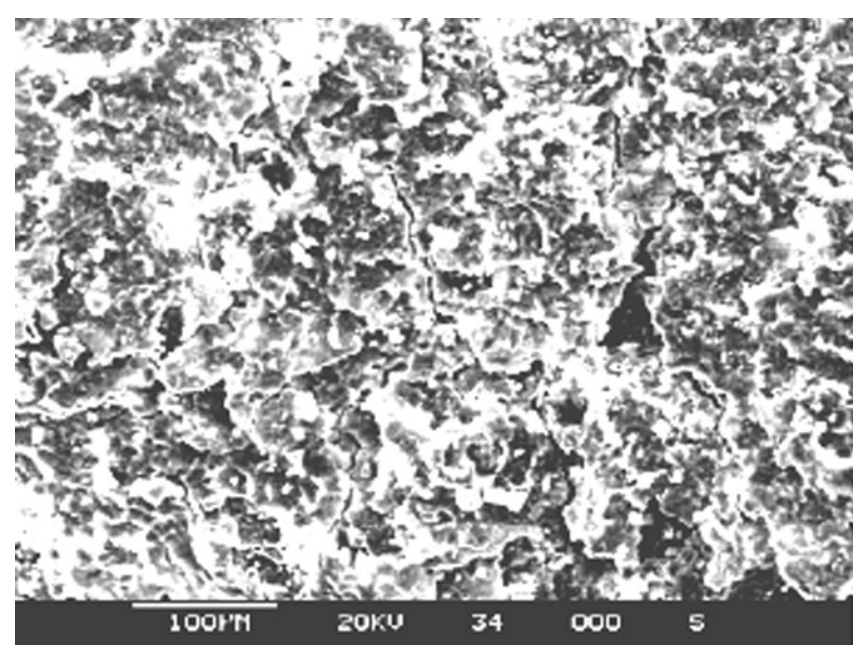

Figure 3. Surface morphology of microarc oxidation ceramic coating $(300 \mathrm{~V}, 3 \mathrm{~A}, 70 \mathrm{~min})$. ffers from amorphous film phase structure after the anodic oxidation of magnesium alloy in principle. Microarc oxidation makes oxidized amorphous $\mathrm{MgO}$ into cubic through high-temperature and -pressure instant sintering. Such structures can make the dense layer denser to increase the hardness and corrosion resistance of magnesium alloy. The formation of $\mathrm{MgSiO}_{3}$ phase indicates that ions in the solution have directly engaged in chemical reactions near the microarc zone (Rama et al 2003).

\subsection{Electrochemical corrosion experiment}

Figure 5 shows polarization curves of original sample and testing samples treated through microarc ceramic coating oxidation in $3.5 \% \mathrm{NaCl}$ solution. It can be seen from the results that the anodic polarization curve of original Y1 sample enters into active dissolution zone when the potential reaches $-1588 \mathrm{mV}$.

The anodic current density increases with the potential increasing within this zone. When the potential reaches $-1420 \mathrm{mV}$, the curve goes into the passivation zone or stable passivation zone. When the potential reaches $-1360 \mathrm{mV}$, the curve goes into the over passivation zone, in which the anodic current density increases with potential increasing at this time. The anodic polarization curve of testing samples treated through microarc oxidation goes into the active dissolution zone when the potential reaches $-1532 \mathrm{mV}$, in which the anodic current density of metal electrode increases with the potential increasing; it goes into the passivation zone or stable passivation zone on reaching $-1400 \mathrm{mV}$, in which the current density is independent of the potential, i.e. the dissolution speed of metal anode remains unchanged within a wide potential range, and it goes into the over passivation zone when reaching $-916 \mathrm{mV}$, in which the anodic current density increases with potential increasing at this time.

The Tafel extension method (Weifang et al 1985) is used to measure corrosion current densities and corrosion

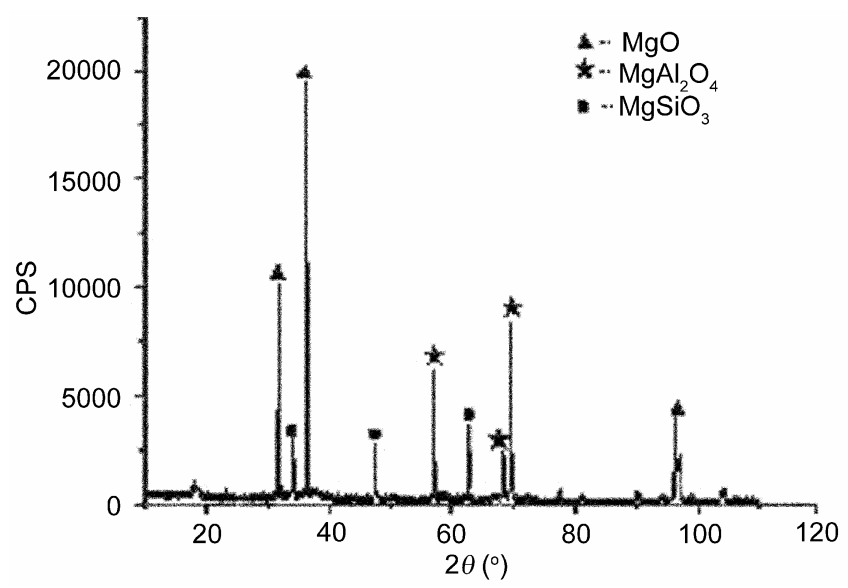

Figure 4. Diagram showing XRD of microarc oxidation. 
Table 1. Results of electrochemistry corrosion.

\begin{tabular}{lcccc}
\hline Samples & $\begin{array}{c}\text { Over passivated } \\
\text { potential }(\mathrm{mV})\end{array}$ & $\begin{array}{c}\text { Corrosion } \\
\text { potential }(\mathrm{mV})\end{array}$ & $\begin{array}{c}\text { Corrosion current } \\
\text { density }\left(\mathrm{mA} / \mathrm{cm}^{2}\right)\end{array}$ & $\begin{array}{c}\text { Corrosion speed } \\
(\mu \mathrm{m} / \mathrm{s})\end{array}$ \\
\hline Y1 & -1360 & -1420 & 0.452 & $10 \cdot 193$ \\
Coating & -916 & -1400 & 0.152 & 3.428 \\
\hline
\end{tabular}
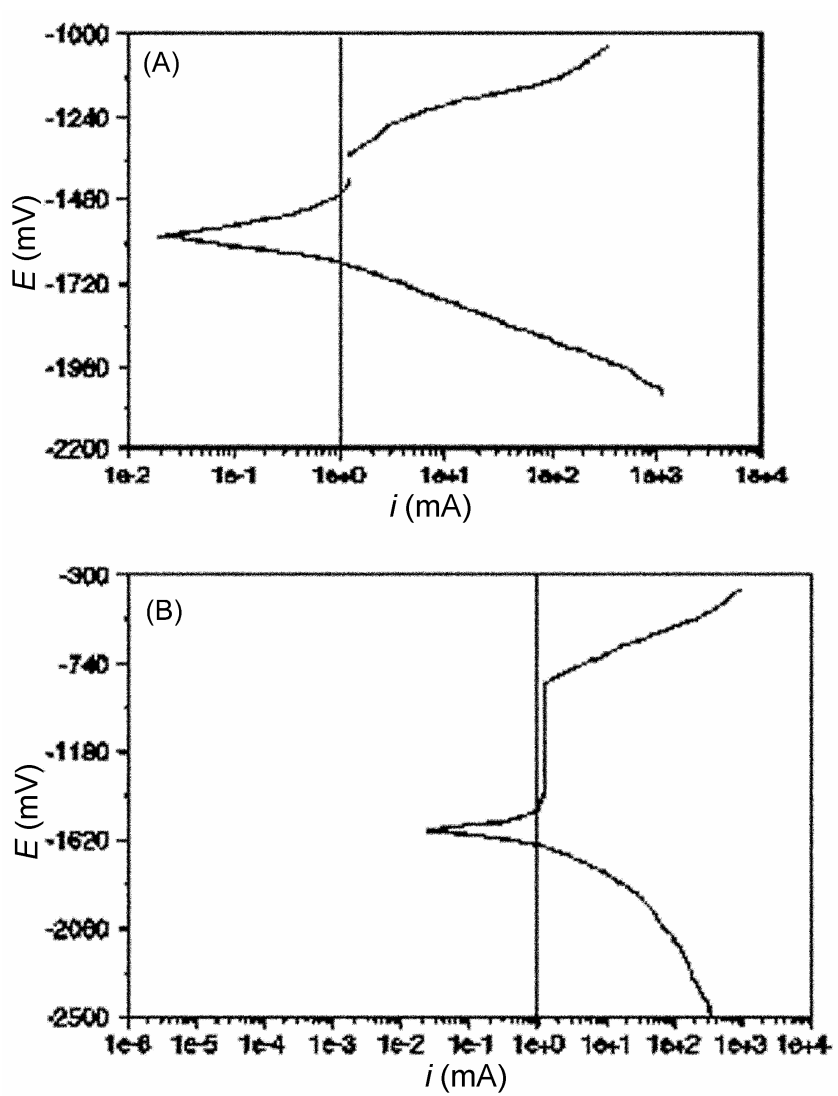

Figure 5. Polarization curves of samples: (A) polarization curve of $\mathrm{Y} 1$ and $(\mathbf{B})$ polarization curve of the ceramic coating.

speeds. Results are shown in table 1. Data shown in the table indicate that the corrosion speed of Y1 magnesium alloy surface treated through microarc oxidation is 3 times as slow as that of the original material and its corrosion resistance is greatly improved.

\section{Conclusions}

(I) Through microarc oxidation, in situ grown ceramic coating composed of loose, dense and contact layers is directly formed on the surface of magnesium alloy by which its surface property greatly improved.

(II) The corrosion resistance of Y 1 magnesium alloy surface obviously improved in comparison with one of the original material after microarc oxidation. The electrochemical corrosion experiment shows that the corrosion resistance of microarc oxidation ceramic coating improved three times compared to that of the original material.

\section{References}

Apelfeld A V, Bespalova O V and Borisov A M 2000 Nucl. Instrum. \& Meth. Phys. Res. B161-163 553

Bailing Jang, Xianfeng Zhang and Jing Zhu 2003 J. Xian Univer. Technol. 19297

Dittrich K H, Krysmann W and Kurze P 1984 Cryst. Res. \& Technol. 1993

Gnedenkov S V, Khrisanfova O A and Zavidnaya A G 2001 Surf. Coat. Technol. 145

Jiang Bailing, Zhang Feng and Zhu Jing 2004 Metal Heat Treatment 2923

Kurze P 1994 Metallober flache 48104

Kurze P and Krysmann W 1986 Cryst. Res. \& Technol. 211603

Rama Krishna L, Somaraju K R C and Sundararajan G 2003 Surf. Coat. Technol. 163-164 484

Robert S and Alivait C 1977 Electrochem. Soc. 1352685

Weifang Zhou 1985 Electrochemistry measure (Shanghai: Shanghai Science Technology) p. 290

Wenbin Xue and Zhiwei Deng 2000 Thin Solid Film 372114

Wenbin Xue, Yongchun Lai and Zhiwei Deng 1997 Mater. Sci. Technol. 589

Wenbin Xue, Zhiwei Deng and Yongchun Lai 1998 J. Am. Ceram. Soc. 811365

Wenbin Xue, Zhiwei Deng and Tonghe Zhang 1999 Rare Metal Mater. \& Eng. 28353

Wirta G P and Brown S D 1991 Mater. Manuf. Process 687

Zozulin A J and Bartak D E 1994 Metal Finishing 9239 